\title{
The function of election campaigns in a developing democracy: the case of South Africa
}

\author{
Lynette Fourie ${ }^{1}$ \\ School for Communication Studies, North West University, \\ Potchefstroom, South Africa. \\ Neeltje du Plessis \\ Department of Marketing and Communication Management, University \\ of Pretoria, Pretoria, South Africa.
}

- This article investigates the unique challenges facing political parties in terms of their communicative responsibilities in a developing democracy as demonstrated by the electoral communication of political parties in the National Elections in South Africa over the past 14 years. Election posters, radio and television advertising messages were analysed and discussed in the light of the informational and interpretational functions of political parties. Messages were analysed in terms of the use of emotional and cognitive message structures, the use of negative messages in comparing party policies on specific issues, as well as the portrayal of leaders. Messages were also analysed to determine whether they had contributed to the advancement of the political debate in a developing democracy.

- The conclusion is reached that the communicative responsibilities of political parties imply that they ideally should assist voters in reaching informed decisions, stimulate public debate on politically sensitive issues without harming democracy, and encourage citizens to exercise their democratic responsibility to participate in the democratic process.

\footnotetext{
${ }^{1}$ Correspondence to: Lynette Fourie, School of Communication Studies, North West University, Potchefstroom, South Africa.

E-mail:Lynette.fouriednwu.ac.za
} 


\section{Introduction}

The 2009 South African General Elections marked 14 years of democracy in South Africa, which included four national and provincial elections and three local elections since 1994. Compared to other young democracies in Africa, South Africa has experienced a relatively stable transition to democracy. This might be attributed to south Africa having a dominant party system, which had been effective at the time, but is not an ideal situation for the sustainable functioning of a democracy. However, within a broader context of a developing society, the South African democracy could be viewed as a developing democracy.

When looking at established western democracies, there is increasingly a call for the professionalization of political marketing which implies that electioneering has become a strategic function of political parties. Coinciding there has progressively been talk of a permanent campaign and is campaigning no longer and ad hoc activity confined to elections.

As a developing democracy it is supposed that South African political parties would take cognisance of the above-mentioned trends regards political marketing in developed democracy, they should also keep in mind that south Africa has a dominant party democracy. This implies that merely campaigning to win elections would be futile; political parties should also employ other strategies. Against this background this article investigates the function of political campaigning in a developing democracy. As a point of departure, some theoretical guidelines will be outlined against which the south African elections are discussed.

\section{The role of communication in a developing democracy}

Democratic elections are only a technical transition and for democracy to be sustainable, citizens have to value the intrinsic democratic values of the system. In this regard some measures for democracy have been developed. Bratton and Chang (2006, pp.1065-1066) identified political stability, government effectiveness, regulatory quality, the rule of law and control of corruption as indicators for so-called stateness, while Bollen (2009, p.370) refers to a continuum of democracy indicating the extent to which political liberties and 
democratic rule are being upheld in a country. Democracy should therefore not be evaluated only in terms of its achievements, but also as a qualitative dimension reflecting the political culture of a system. This process of learning and internalising political values is called political socialisation in which communication plays a central role.t

The role of the media in democracy can be categorised as either informational or interpretational. In established liberal democracies the informational function is well recognised and it is assumed that the media also have a watchdog role to play, thereby limiting the power of government. When considering the normative press models of McQuail (1987, pp.111-123) it is evident that the media's role in developing democracies is somewhat different. Three normative press models specifically apply to developing democracies: the social responsibility model, the developmental model and the democratic-participant model. Normative guidelines of these models indicate that it can be assumed that media in developing democracies should be free, but in return it is responsible to actively promote the democracy. In practice this means that sustaining the democracy is more important than the traditional watchdog role of criticising and questioning the government.

It could be argued that political parties in a developing democracy are responsible in their electoral communication to not only canvas votes, but also to contribute to the sustainability or sustainable development of the democracy. Political campaigns should, as in the case of the media, inform the electorate on, and interpret political events. Political information and viewpoints are necessary for a vibrant and sustainable democracy, as inadequate voter knowledge has two negative implications for democracy. Firstly, it prevents democratic governments from reflecting the will of the people in a meaningful way (Page and Shapiro, 1992) and secondly, voter ignorance contradicts the notion that democracy serves the interests of the majority, because uninformed voters can more easily be manipulated by the elite (Gunther and Mughan, 2000; Kuan and Lau, 2002).

\section{Rational versus reasoning voters}

The assumption exists that an informed citizenry is essential for sustaining democracy, however there are different viewpoints on exactly how these informed voters make decisions, namely either rationally or by using reasoning.

According to the rational voter theory, voters make a justifiable choice between political alternatives. This implies that a voter is able to store acquired political knowledge and recall it when necessary in order to come to a decision (Lau and 
Sears, 1986, p.5). This would imply that the voter is dependent on the informational function of the media and political parties. In the context of democracy this is normatively attractive, but practice has shown that few voters are capable of doing this. Studies in the USA (Delli Carpini and Keeter, 1994 and 1996; Friedman, 1998, pp.399-404; Somin, 1998, pp. 416418) and in South Africa (Fourie and Otto, 2009) indicated that voters score low on political knowledge tests. Two explanations for this is that voters do not receive sufficient information from political parties and/or the media; and that they seldom actively seek political information, let alone consciously process and store information for later use. If rational voters are seen as the only persons competent to vote, then there might be only a few competent voters participating in elections. As thousands of voters exercise their right to vote with confidence, it seems that they do have some reason for their choice of a specific party/candidate.

The reasoning voter therefore forms a perception of political reality as it unfolds daily around him/her (Popkin, 1991, pp.44-71). To understand this on-line processing model (OL-model) a distinction is made between experiencing and evaluating events. According to the OL-model, it is not the event itself that is stored in memory, but the evaluation and interpretation thereof (Lodge, Steenbergen and Brau, 1995, p.10). This implies that although voters are not able to recall factual political information, it does not mean that they are not capable of functioning as democratic citizens. Voters only store their decisions in memory, not necessarily the reasons for their decisions. They therefore know whom to vote for, without being able to motivate their decision. The reasoning voter thus depends on the media and political parties to interpret events.

In practice, voters seem to use a combination of these methods to make decisions. Both the informational and interpretational functions of the media and political parties play a part in sustaining democracy. In the case of political parties, the focus will be more on the interpretation function, as each party interprets the political reality according to its own policy. In developing democracies the way in which this information and interpretation functions serve democracy is important, for example what picture do political parties paint of democracy through their interpretation functions? 


\section{Political Campaigning in South Africa}

The South African Constitution (Par.16.1 a. and b.) guarantees freedom of expression which includes freedom of the press and other media, as well as freedom to receive or impart information or ideas. Paragraph 19.1 c. guarantees the freedom to make political choices, including the right to campaign for a political party or cause (South African Constitution, 1996).

\section{Freedom to campaign}

Apart from this basic right to campaign, political parties also sign a code of conduct pledging their commitment to free and fair elections. However, in reality financial constraints influence equal opportunities to campaign. To equalise electioneering opportunities, free air time was allocated by the Independent Communication Authority of South Africa (ICASA) and the Independent Electoral Commission (IEC) to parties for both radio (since 1994) and television (since 2009) advertising. The basic assumption had been that all political parties should be treated equitably (which should be understood as fair rather than equal). It was argued that the public has a right to hear more from parties with more influence; thus larger parties were allocated more time (Teer-Tomaselli, 2006). According to the ICASA regulations, the South African Broadcasting Corporation $(\mathrm{SABC})$ was required to provide four timeslots of two minutes per day for public election broadcasts (PEBS).

Although parties received free media time, they were responsible for their own advertising production costs, giving the parties with larger budgets another advantage. South African political parties also receive state funding for their election campaigns based on their representation in the national parliament and provincial legislatures, which means that bigger parties are favoured above smaller parties (Lemon, 2009, p.670). Political parties could also buy advertising time on radio and television. This advantaged the larger parties and only the African National Congress (ANC) and Democratic Alliance (DA) therefore bought time for television advertising in the 2009 elections. 


\section{Information and interpretation functions of political parties}

Apart from ethical electoral conduct, political parties are also responsible for their information and interpretation functions in a young democracy. They are expected to:

- empower the electorate to make informed voting decisions;

- stimulate public debate by highlighting important political issues, without threatening the stability of the democracy;

- motivate voters to participate in elections; and

- contribute to a democratic political culture by emphasising democratic values.

Even in established democracies the ethical implications for campaigning in a democracy is debated. In the following section some of the issues which could influence these responsibilities will be discussed, including the use of emotional and cognitive messages, negative messages and identification of democratic values and issues affecting democracy.

\section{Using emotional and cognitive messages}

It is not always easy to distinguish between image messages, spin doctoring and persuasive appeals in literature. They are therefore grouped together here as emotional messages. Issue messages are also not clearly defined. Sometimes an issue refers to a policy issue, while in other instances it implies that an issue must be explained and contextualised (Johnson-Cartee and Copeland, 1997, pp.156-157; Johnston and Kaid, 2002). In this regard the term cognitive message will be used, indicating that an issue needs to be explained and contextualised in order to include the voter in the public debate.

Political parties are often accused of focusing more on images instead of issues in election campaigns, and consequently not adequately empowering the voter. However, Holtz-Bacha and Kaid (2006, p.449) found in a comparative analysis of political spots in different countries that the majority of television advertisements focused on issues. In young democracies, the results were reversed and they concluded that emerging democracies focus less on issues in their spots than the more established democracies. Does this mean that political parties are not fulfilling their information and interpretation function? This criticism is often directed against political parties in the context of assuming that they have only an informational function. However, it had been established above that voters should not merely be seen as rational, but also as 
reasoning individuals. Therefore, as voters process information differently the approaches in the messages should also differ.

Furthermore, emotional and cognitive messages are not necessarily opposites of each other, as some policy issues could elicit emotional responses. Way and Masters (1996) argue that both emotional and cognitive messages form part of the decisionmaking process. Emotion is the process which activates a stimulus, while cognition is the processing, interpretation and storing of information. This implies that a voter seeing a candidate on television could react emotionally while at the same time there is a cognitive reaction through which specific policy issues are associated with the candidate. This cognitive response could impact on the emotional response by reinforcing or adjusting it. Therefore both emotion and cognition contribute to the voting decision. The one is not 'better' than the other. Both have significance in electioneering. Emotional messages are used to attract the voter's attention, followed by cognitive messages contextualizing the emotional message and relating it to a policy issue or democratic value. Even personal characteristics of party leaders could be linked to policy issues.

Less sophisticated voters, as is often found in developing democracies, tend to use shortcuts to help them make their choice. Emotional messages often function as such shortcuts (Conover and Feldman, 1989; Popkin, 1991, p.59). Within the South African context it could be assumed that emotional messages play an important role in the voters' decisions. What is questionable on an ethical level is whether the party image is a true reflection of its policies and thus empowers voters, or whether it is being used to manipulate them. Emotion in political campaigns should be used responsibly, especially in a young democracy.

\section{Using negative messages}

Generally negative messages indicate why voters should not vote for a particular party or candidate by indicating why the party or candidate is not fit to govern. The tone of negative messages vary, with some taking a personal attack approach that is sometimes referred to as attack messages, and others comparing viewpoints.

Negative messages: demobilising or mobilising?

Concerns regarding the use of negative messages include that it might demobilise the electorate, or result in mudslinging, thereby blurring true election issues and threatening the stability of democracy. In the early 1990s research indicated 
that negative messages could demotivate voters regarding politics, leading to general apathy toward politics and a decline in voter turnout (Ansolabehere, Iyengar, Simon and Valentino, 1994; Ansolabehere and Iyengar, 1995). Although this finding was supported by later authors (Abbe and Hernson, 2000; Turner, 2001; Rahn and Hirshorn, 1999), it was not conclusive. Some researchers have even concluded that negative messages motivate people to vote, as they are usually remembered better and their emotional appeals lead to greater electorate participation (Wattenberg and Brains, 1999, p.896; Kahn and Kenney, 1999, p.878).

Influencing public political debate

Negative messages also have the potential to stimulate public debate. However, the tone of the message could influence its informational value. Although messages comparing policy viewpoints or highlighting faults in other parties' policies could contribute to political debate and strengthen democracy, messages resulting in mudslinging could threaten the stability of a growing democracy. However, when personal attacks on political leaders reveal corrupt behaviour, or behaviour threatening sustainable democracy, it can be considered unethical.

It is clear that negative messages should be used with caution in a young democracy. There is a further distinction between two kinds of negative messages. In a young, diverse democracy negative messages aimed at discrediting leaders (without sound reasons) or insulting other groups are regarded as detrimental to democracy and not supportive of social harmony. On the other hand, messages stimulating debate, within the boundaries of social harmony, could contribute to the building of a democratic culture of public debate.

\section{Promoting democratic values}

Political advertisements should ideally also actively promote core democratic values. Whereas emotional messages could serve as a shortcut to attract voters' attention, cognitive messages should be related to policy issues, indicating how these issues contribute to sustaining democracy.

\section{Examples from South African election campaigns}

The following discussion investigates the use of emotional and cognitive messages, negative messages as well as the role of political messages in encouraging political participation in a young democracy. 


\section{Using emotional and cognitive messages}

In election campaigns since the 1999s, two issues stand out, namely crime and poverty. Crime was mostly emphasised by opposition parties to the ANC, while poverty was emphasised by the ruling party (currently the ANC).

Crime as electoral issue

The poster campaigns of the opposition parties consistently addressed crime as an emotional issue, linking it to the abolishment of the death penalty in the 1999-election campaigns, for example: New National Party (NNP) (Restore the death penalty), and Freedom Front ( $F F$ ) (Yes for the death penalty). Although the Democratic Alliance (DA) did not refer to the death penalty, they also took a tough stance on crime: (Nail them and jail them) in 2000, (150 000 police officers) in 2004 and (Zero tolerance for criminals) in 2006. Similarly, the 1999-poster campaign of the NNP also referred to (No mercy for criminals). Although the issue of crime was not that prominent in the 2009 posters, the Freedom Front Plus (FF+) still referred to crime on their posters (Stand up against crime).

Crime as an issue had also been prominent in radio advertisements from 1999 onwards and in television advertisements in 2009. Examples of emotional appeals regarding crime in radio advertisements were:

- Crime is threatening the very fabric of society, no one is safe anymore. • • (NNP 1999)

- The news from South Africa: Since the ANC took power an average of 132 women raped every day. An average of 71 South African's: whites, blacks, coloureds, and Indians murdered every day • • . (DP, 1999)

- . . the criminals seems to have more rights than us law abiding citizens . . (ACDP 2004)

- Murder, rape, child abuse and the criminals get away with it. South Africa deserves better: the DA will put 150 thousand police on our street, train them, equip them and stop the criminals. (DP 2004)

- I never saw them coming, I felt the gun against my head, they demanded my car. I felt like a victim. I want to use my vote to help fight crime. (NNP 2004)

- . . in South Africa is only around 10\% which means that 90\% of criminals are never punished. We have the best plan to prevent crime, catch criminals, prosecute, convict, and punish them properly (DA 2009) 
The same themes were echoed in the television advertisements:

- We live behind barbed-wired fences, what kind of a life is that for our children? (ACDP 2009)

- 99 rapes per day, 38.9 hijackings per day, 651.6 burglaries per day, 292 car thefts per day. (FF+ 2009)

The emotional potential of crime as an election issue was well explored. Two approaches stand out: highlighting the severity of crime, and that crime was a universal problem and that every citizen is a potential victim. Regarding the integration of emotional and cognitive messages, there were examples where political parties linked crime to policy issues, indicating how they would address the issue or what they would have done in this regard. The emotional appeal played on the fear and anger of the electorate to galvanise them into acting by voting against the ANC as ruling party. Therefore the major focus was on the problem of crime in South Africa and the inability of the ANC Government to address the issue.

Poverty as election issue

The second major issue on the South African election agenda was poverty and the related social issues thereof, such as unemployment, health, and education which was mainly addressed by the ruling ANC. In the poster campaigns of the parties, job creation was the only policy issue that the ANC addressed in their poster campaign. The DA also mentioned job creation in 2000 (Jobs for all the people) and in 2004 ( 1 Million real jobs).

\section{INSERT FIGURE 1 AND FIGURE 2 HERE}

In the radio and the television advertisements poverty was linked to its impact on health and education systems. Unemployment and housing were still used as emotional hooks to attract the voters' attention but the policy issues were also contextualised within the ambit of social problems typical of a developing society. The ANC emphasised their achievements and looked forward to what needs to be done in future.

- Together we have brought electricity, water, and other services to millions of homes. Today 750 thousand additional families have a roof over their heads on land that belongs to them, but more work lies ahead, together we must step up the fight for a better life for all, we must speed up change with renewed determination (ANC 1999). 
- My children mean the world to me, I want see them grow up and build a good future for themselves; they deserve to be fed and taken care of. I want to use my vote to improve education (NNP $2004)$.

- A government committed to improving the lives of all south Africans. So vote for the ANC to create work and fight poverty (ANC 2004).

- The DA plan: create 1 million real jobs, by pushing foreign investment and funding small business. Vote DA for real change, because South Africa deserves better (DA 2004).

Television advertisements linked in with these messages:

- Back in my father's days they could only find work on farms or mines they use to dream of a better life. . . (ANC 2009).

- We have seen people receive free houses (ANC 2009).

- . have access to clinics and hospitals (ANC 2009).

- . . schools have been built for our grand children (ANC $2009)$

As ruling party the ANC relied strongly on their past achievements in terms of service delivery, health, job creation, housing, et cetera. However, the ANC electioneering messages also acknowledged that poverty had not yet been successfully addressed and more work lies ahead. Their advertisements recognised the complexity of a developing society and also that these issues are interrelated. They did not propose a quick-fix which could raise unrealistic expectations.

Presentation of the party leader

In South African elections the electorate votes for political parties and not for candidates. Although election campaigns in South Africa do not focus primarily on a party leader, these leaders do play a significant role. The iconic value of a leader had been demonstrated in the 1994 and 1999 campaigns of the NNP and the ANC referring back respectively to FW de Klerk and Nelson Mandela. In 1999 the NNPs campaign reflected the fact that Marthinus van Schalkwyk was still establishing himself as leader after succeeding FW de Klerk. In this regard the NNP had a print advertisement where De Klerk declared his support for Van Schalkwyk and a radio advertisement where FW de Klerk stated: Dagsê. Vir my, FW de Klerk, is daar net een party in die komende verkiesing, die NNP onder bekwame leierskap van Marthinus van Schalwyk. (Translation: Good day. For me, FW de Klerk, there is only party in the coming election, the NNP under the capable leadership of Marthinus van Schalkwyk). In the 2004 
elections the NNP again had a radio advertisement featuring $\mathrm{FW}$ de Klerk: Mr FW de Klerk has made his choice for this election. I support the concept of taking hands in resolving the big problems our country faces.

Nelson Mandela as a political icon constantly played an important role in the ANC election campaigns. The ANC still referred to him in their 2009 television campaign: I wonder if Mandela and them ever thought they'd see a free South Africa (my dream); When Madiba was released . . that was the beginning of an existing road (my vote).

When Tony Leon was leader of the DA, he formed an important part of their campaign. The DA presented an interesting example of how the changing face of a party leader coincided with a change in electioneering strategy. During the 1999 fight back election campaign a very sturdy Leon was featured wearing a tie. His folded arms contributed to the image of inaccessibility and toughness. This tough image of Leon was enhanced by the slogan: The guts to fight back which was echoed in the radio advertisements: I am Tony Leon, Democratic Party leader. Show your courage. Fight back. Vote DP.

In contrast to that, the DA's campaign in 2000 focused on inclusiveness and the theme was: For all the people. Within this context a completely transformed Leon was portrayed with open hands and a smile. He was also less formally dressed and seemed more accessible and relaxed. Leon had a much lower profile in the radio advertisements and also had a more reconciling approach: I am Tony Leon, together with our partners we can win 30\% of the vote on 14 April and challenge the ANC for power over the next five years. But only if every opposition voter comes out and vote DA.

This more approachable image was continued during the 2004 general elections, with a close-up photo of a still smiling Leon. In addition to this poster he was featured amongst a crowd, projecting the image of one of the people, referring to more jobs and less crime. The same photo of Leon was used during the 2006 local elections with the campaign slogan the: DA delivers.

\section{INSERT FIGURE 3 HERE}

In the 2009 elections, the DA again portrayed itself as a tough opposition party, emphasising that the DA was the only party that was big enough to be an effective opposition to the ANC. This appeal was lodged against the background of the introduction of Congress of the People (COPE) which the DA hoped would split the ANC vote. Helen Zille, as new DA party leader, had a high profile in the DA's election campaign and her voice was heard in nearly all the radio messages. 


\section{The use of negative messages in South African elections campaigns}

Negative messages have mainly been used by the opposition parties. In no campaign has there been an excessive use of negative messages, but there are examples of it in all the campaigns. In certain instances, warning lights flicker regarding the use of negative messages and the sustainability of democracy. However, because negative messages were almost exclusively used by the opposition parties, only a minority of the voters were exposed to these messages, which would have minimised their effects.

The use of negative messages in South African campaigns are now discussed by referring to negative advertisements highlighting issues, comparing policy issues, aimed as specific leaders and contributing to political debate.

Identifying issues

The Democratic Party (DP) in 1999 and the DA in 2004 framed crime as an issue that the ANC had not been able to manage successfully. These messages could be seen as highlighting problems in society and also stimulating debate. The DP's focus on crime should be seen within the context of referring to the power of the voter implying that if voters wanted to achieve change, they had to vote. In that sense voters were empowered. This message was intended to counter the feeling amongst minority groups that it was futile to vote. However, these messages could have affected the democracy negatively in that they portrayed South Africa in a negative light, implying that the democracy was not functioning as it should, which could leave the electorate feeling despondent. One could argue that human life and liberty were appropriately highlighted and that voters had been oriented with regard to the issues that demanded a responsible decision from them.

Comparing party viewpoints on issues

Negative comparative messages were particularly used during the 1999-election campaigns. The NNP had print advertisements referring to the death penalty, policing and abortion, suggesting that the DP was, in terms of these policy issues, closer to the ANC than to the NNP. Along the same line of thought, the Freedom Front (FF) had a series of print advertisements referring to the Truth and Reconciliation Commission, land claims, illegal removals, abortion, pensions, 
lottery and gambling regulation, suggesting that the ANC, NNP and DP all supported proposed legislation, while the FF opposed it. Although these messages addressed emotional issues, they were generally not presented overly emotionally and could well have stimulated debate and thus enhanced the democracy. The DA also had radio advertisements in the 2009-election campaign comparing the ANC and DA: The choice between the DA and the ANC is a choice between success or failure for South Africa. The DA stands for the open opportunity society for all in which the state protects everyone's rights of freedom and offers opportunities to all. The ANC stands for the closed society in which the state protects the interests of a few powerful politicians who have used their power to benefit their small circle and place them above the law.

Using personal attacks

There were, however, other negative messages in the election campaigns that could have been potentially harmful for a young democracy. In the $\mathrm{DP}^{\prime} \mathrm{s}$ 1999-election campaign there were several examples of personal attacks on leaders, like for example depicting Winnie Madikezela-Mandela in military uniform in a print advertisement with quotes from the Truth and Reconciliation Commission's report finding her guilty of the violation of gross human rights with the caption: Jy kan hierdie vrou stop (You can stop this woman). Similarly Nkozana Zuma's (Minister of Health) picture appeared in an advertisement with the caption: Vertrou jy hierdie vrou met 'n tweederdemeerderheid? Ons ook nie. (Do you trust this woman with a twothirds majority? We neither.)

\section{INSERT FIGURE 4 HERE}

In the DA's 2009-election campaign the same strategy was used regarding Jacob Zuma. In the majority of the DA's radio advertisements the point was made that the DA is the only party that could stop Jacob Zuma: Only the DA is big enough to stop Jacob Zuma. This was supported by their poster campaign. Although not explicitly stated, the assumption was made that Zuma would not be a suitable President. This should be seen against the background that at the start of the 2009 campaign it was not yet clear whether Zuma would be prosecuted for fraud linked to his relationship with shabir shaikh. Although the negative messages were directed at specific persons, it was not necessary bad for democracy. It should be seen within the context that questions were raised whether a person linked to fraud charges would be suitable for President of a democracy. 
This line of messages by die DA was without a doubt controversial, but it did stimulate public debate.

Although the DA's 2009 advertisements contained negative messages against the ANC and Jacob Zuma, these could also be seen as strengthening one of the principles of democracy, namely a strong opposition. The negative messages against the ANC per se were limited to highlighting corruption: The ANC stands for a closed society in which the state protects the interests of a few powerful politicians who have used their power to benefit their small circle and place them above the law. It could be argued that the DP were referring to the leaders' track records and indicating they were not suitable leaders in a democracy.

Contributing to political debate

In 2004 the DA began targeting other opposition parties besides the ANC. Their campaign theme was to unite the opposition and this was especially deployed in their radio advertisements. They had a series of advertisements with the message that the DA and its partners could win 30\% of the vote. They all ended with the slogan: Unite behind the DA and help build a new majority in South Africa. The unite-the-opposition-theme was also echoed in their poster and pamphlet campaigns. Underlying this was the notion that a vote for a smaller party would be a "wasted" vote. In two of these advertisements the DA named the FF+ and ID and implied that a vote for them will be a wasted vote, for example: I was thinking of voting for Patricia de Lille's Independent Democrats, but I am not going to. I am voting DA instead, because I don't want to split the opposition and South Africa needs a strong alternative to the ANC. I like De Lille, but she is really just a one-woman show. . .

Although it was not explicitly stated that a vote for the NNP would be wasted, the DA inferred that a vote for the NNP would be a vote for the ANC and therefore a vote against the opposition: Marthinus van Schalkwyk has betrayed NNP supporters in exchange for a job. He gave the ANC power. If you vote NNP you will give the ANC power in the Western Cape again. Keep the ANC out.

The DA continued the theme 2009 that a vote for a smaller party will be a wasted vote: The DA is the only party that is big enough to beat the ANC and offer a real alternative. If the opposition vote is divided the ANC wins. When you vote DA you can be absolutely sure that we won't give your vote back to the ANC by going into a coalition with them. You can't be sure of that with any other party.

The FF+ reacted to this style of campaigning: The DA is now suddenly attacking other opposition parties in the media, how short sighted. After the previous local elections no single 
party could govern in cape Town. Without the cooperation of the so called smaller parties Helen zille would not have been the Mayor of Cape Town today and the DA would not lead a coalition there or anywhere else. With a multiparty coalition it could be done again. Let's keep to honest politics (Translated from the original Afrikaans). Although this kind of electioneering could turn to mudslinging and parties losing sight of important policy issues, this specific case also had the potential to empower the electorate. This public debate referred to technical issues regarding the electoral system which could have prompted the electoral to learn more about the specific voting system and the forming of coalition governments.

\section{Building of democratic values}

Informing the electorate alone is not enough to sustain democracy; the content of the information is also important. As was indicated previously, one of the functions of political parties in a young democracy is to build a democratic culture by promoting democratic values. This implies that electioneering should induce a climate conducive to democracy.

\section{Encouraging political participation}

Civil society plays an important part in curtailing the power of the ruling party. Although political parties are not part of civil society, as they seek power to rule the country, they do play an important part in civil society. It could therefore be expected of political parties to make statements that reflect their different policy viewpoints and encourage democratic participation. Nearly all the posters implored voters to vote, but then for a specific party. A closer look, however, reveal that some of the posters actually encouraged voters to vote because it was their democratic right (responsibility).

The ACDP poster in the 1999-election campaign Watch think act! could be seen to speak to voters' sense of rationality. It emphasised that the act of voting was not merely an emotional one, but one which implied responsibility. Although some viewed the "fight back" campaign of the DP as negative, the campaign also promoted political participation. The poster: You have the power fight back tells the voter that by voting they can act; they can have a say in government. When seen in context with the other posters, it implied that by voting the citizen could do something about crime, corruption, et cetera, by exercising their democratic responsibility. The DA also had a poster in their 2004 campaign assuring voters they can vote even if they are on holiday. The national vote could be brought out in any voting district. The importance of the a strong opposition which 
was central in the $\mathrm{DA}^{\prime}$ 's 2004 and 2009 election campaigns could also be seen as encouraging voters to vote in order to promote and sustain democracy .

\section{Conclusion}

This article glanced at the unique challenges and problems facing political parties in young democracies. As is in the case of the media, opposition parties should actively be involved in working towards a sustainable democracy. Political parties have an information and education function in a democracy. These functions should contribute to:

- Empowering the electorate to make informed decisions for whom to vote. In providing information to the electorate parties should keep in mind that voters process information differently and therefore should be variety in the message strategies of political parties. Emotional messages should be used to attract the attention of the reasoning voter, but should also be contextualised in the context of policy issues, thus empowering the voter.

- Stimulating public debate by highlighting important political issues. It is the task of political parties to critically evaluate the political scene during election campaigns. In a developing democracy this should be done with utmost care, as mere critique could destabilise the democracy. From the ruling parties' perspective it is important to indicate what it has achieved, especially within the framework of democracy and from the opposition parties' perspective it is important to highlight issues that could threaten the sustainability of democracy.

- Motivating voters to exercise their democratic right to participate in elections by emphasising the importance to participate in the electoral process. It is not just important to canvas votes; voters must be led to understand why they vote and how the democratic process works.

- Contributing to a democratic political culture by emphasising democratic values. Through their educational and interpretational function political parties bring a specific political reality to the voters. This reality should contribute to the voter's perception and understanding of democracy and enhance democratic conduct. Furthermore, political parties should in their campaigns take care not to make statements that could have long term negative effects on the democracy. 


\section{References}

Abbe OG, Hernson PS. 2000. Going negative not always mean getting ahead in elections. Campaigns and elections 21(1):7779.

Ansolabehere S, Iyengar, S. 1995. Going negative: how political advertisments shrink and polarize the electorate. Macmillan: New York.

Ansolabehere S, Iyengar, S, Valentino N. 1994. Does attack advertising demobilize the electorate? American political science review $88(4): 829-838$.

Bollen K. 2009. Liberal democracy series I, 1972-1988: Definition, measurement and trajectories. Electoral studies $28: 368-374$.

Bratton M, Chang, ECC. 2006. State building and democratization in Sub-Saharan Africa: Forwards, backwords or together. Comparative political studies 39(9):1059-1083.

Conover PJ, Feldman, S. 1989. Candidate perception in an ambiguous word: campaigns, cues and inferences processes. American Journal of Political Science 33(4):912-940.

Delli Carpini MX, Keeter S. 1994. Effects of the news media environment on citizen knowledge of state politics and government. Journalism Quarterly $71(2): 443-457$.

Delli Carpini MX, Keeter S. 1996. What American's knows about politics and why it matters? Yale University Press: New Haven.

Fourie LM, Otto H. 2009. Political knowledge and media usage patterns of North-West University students during the 2009 general election. Paper presented at the annual conference of the South African Communication Association held at the North West-University. September 2009.

Friedman S. 1998. Introduction: public ignorance and democratic theory. Critical Review 12 (4):397-411).

Gunther R, Mughan A. 2000. The political impact of the media: reassessment. In Democracy and the media: a comparative perspective, Gunter R, Mughan A (eds). Cambridge University Press: New York.

Holtz-Bacha C, Kaid LL. 2006. Political advertising in international comparison.In the Sage Handbook of political advertising, Holtz-Bacha C, Kaid LL (eds). Sage: Thousand Oaks. 
Johnson-Cartee KS, Copeland GA. 1997. Manipulation of the American voter - political campaign commercials. Praeger: Westport.

Johnston A, Kaid LL. 2002. Image ads and issue ads in US Presidential advertising: using video style to explore stylistic differences in televised political ads from 1952- 2000. Journal of Communication Research 52 (2):281-301.

Kahn KF, Kenney PJ. 1997. A model of candidate evaluations in senate elections: the impact of campaign intensity. Journal of politics $59(4): 1173-1205$.

Kuan H-C, Lau S-K. 2002. Cognitive mobilization and electoral support for the Democratic Party in Hong Kong. Electoral Studies $21(4): 651-582$.

Lau RR, Sears DO. 1986. An introduction to political cognition. In Political cognition: the $16^{\text {th }}$ annual Carnegie Symposium on cognition, Lau RR, Sears DO (eds). Lawrence: Hillsdale.

Lemon A. 2009. The general election in South Africa, April 2009. Electoral Studies:647-673.

Lodge M, Steenbergen MR, Brau S. 1995. The responsive voter: campaign information and the dynamics of candidate evaluation. The American Political Science Review 89(2):309-326.

McQuail D. 1987. Mass communication theory: an introduction. Sage:London.

Page BI, Shapiro RY. 1992. The rational public: fifty years of trends in America's policy preferences.University Press: Chicago.

Popkin S. 1991. The reasoning voter: communication and persuasion in presidential campaigns. University Press: Chicago.

Rahn W, Hirshorn RM. 1999. Political advertising and public mood: a study of children's political orientations. Political communication $16(4): 387-407$.

South African Constitution. 1996. [Online] Available from: http://www.info.gov.za/documents/constitution/1996/96cons2. htm

[September 2010].

Somin I. 1998. Voter ignorance and the democratic ideal. Critical Review 12 (4):413-457. 
Teer-Tomaselli R. 2006. Political advertising in South Africa. In The sage handbook of political advertising, Holtz-Bacha C, Kaid LL (eds). Sage: Thousand Oaks.

Turner J. 2001. The negative campaign: New Labour, Ken Livingstone and the London mayoral selection process. Media culture and Society $23(2): 257-265$.

Wattenberg MP, Brains CL. 1999. Negative campaign advertising: demobilizer or mobilizer". American Political Science Review, $93(4): 891-899$.

Way BM, Masters RD. 1996. Emotion and cognition in political information processing. Journal of Communication, 46(3):48- 66. 


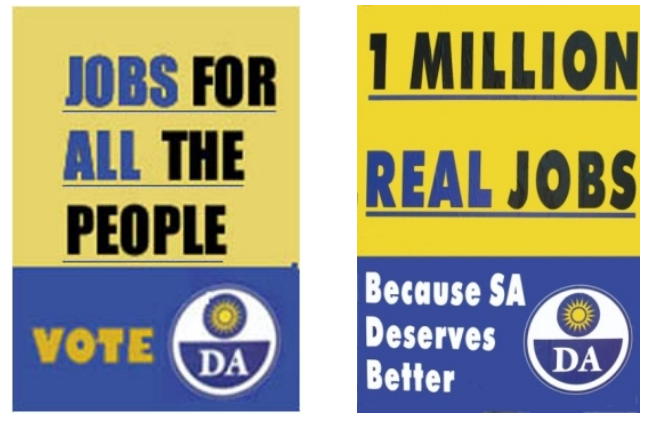

Figure 1: 2000/2004 DA posters

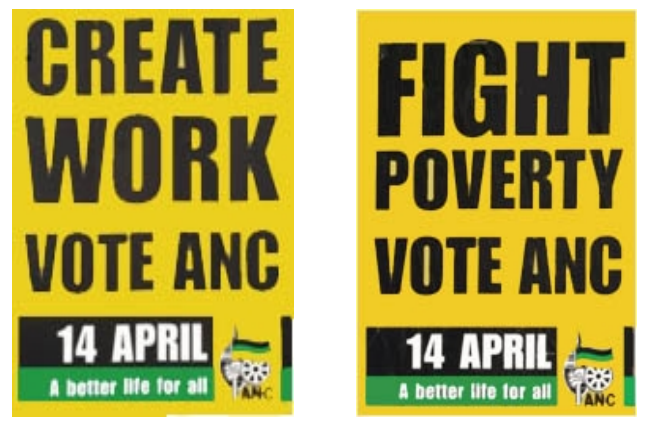

Figure 2: 2004 ANC posters 
Figure 3: DA election posters.

'SA deserves better' 'The DA delivers'

DP: 1999

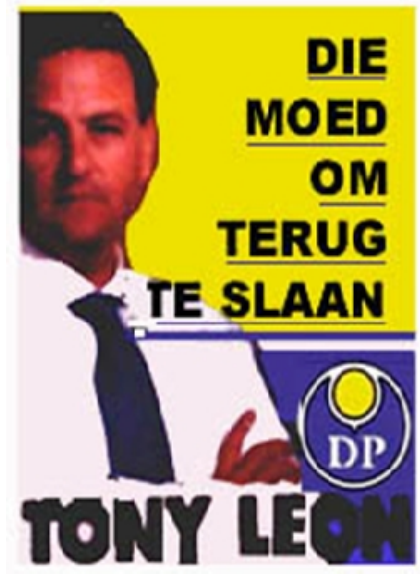

DA: 2000

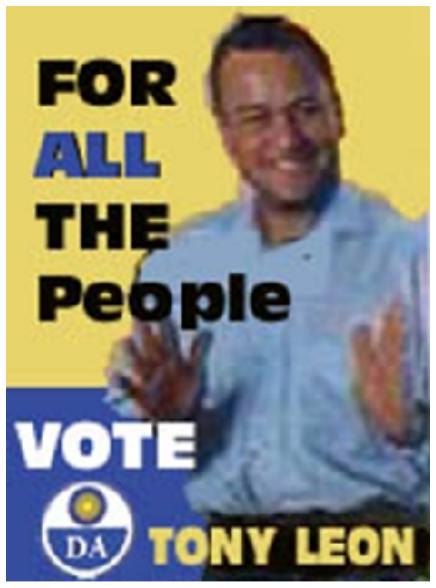

DA: 2004

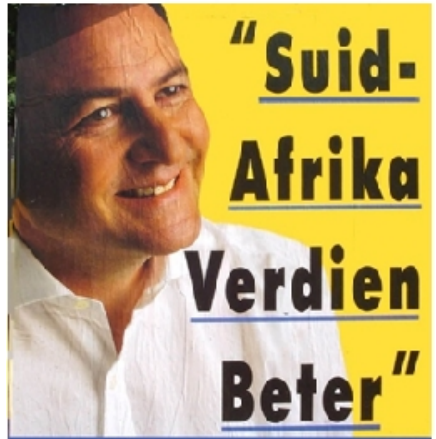

Stem DA vir

ware verandering DA
DA: 2006

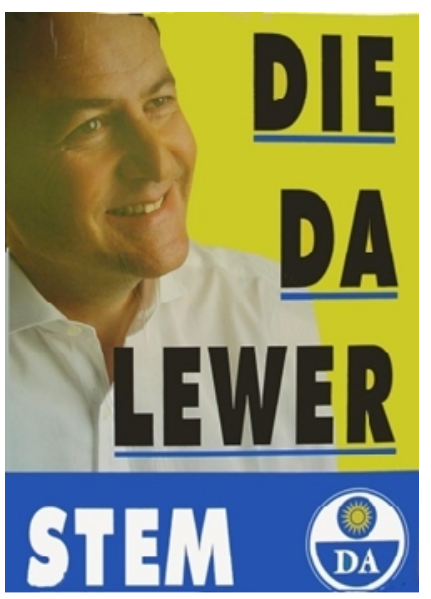


Figure 4: 1999 DP advertisements

$\begin{array}{ll}\text { 'You can stop this woman' } & \text { 'Do you trust this woman with } \\ & \text { two-thirds majority? We } \\ & \text { neither.' }\end{array}$
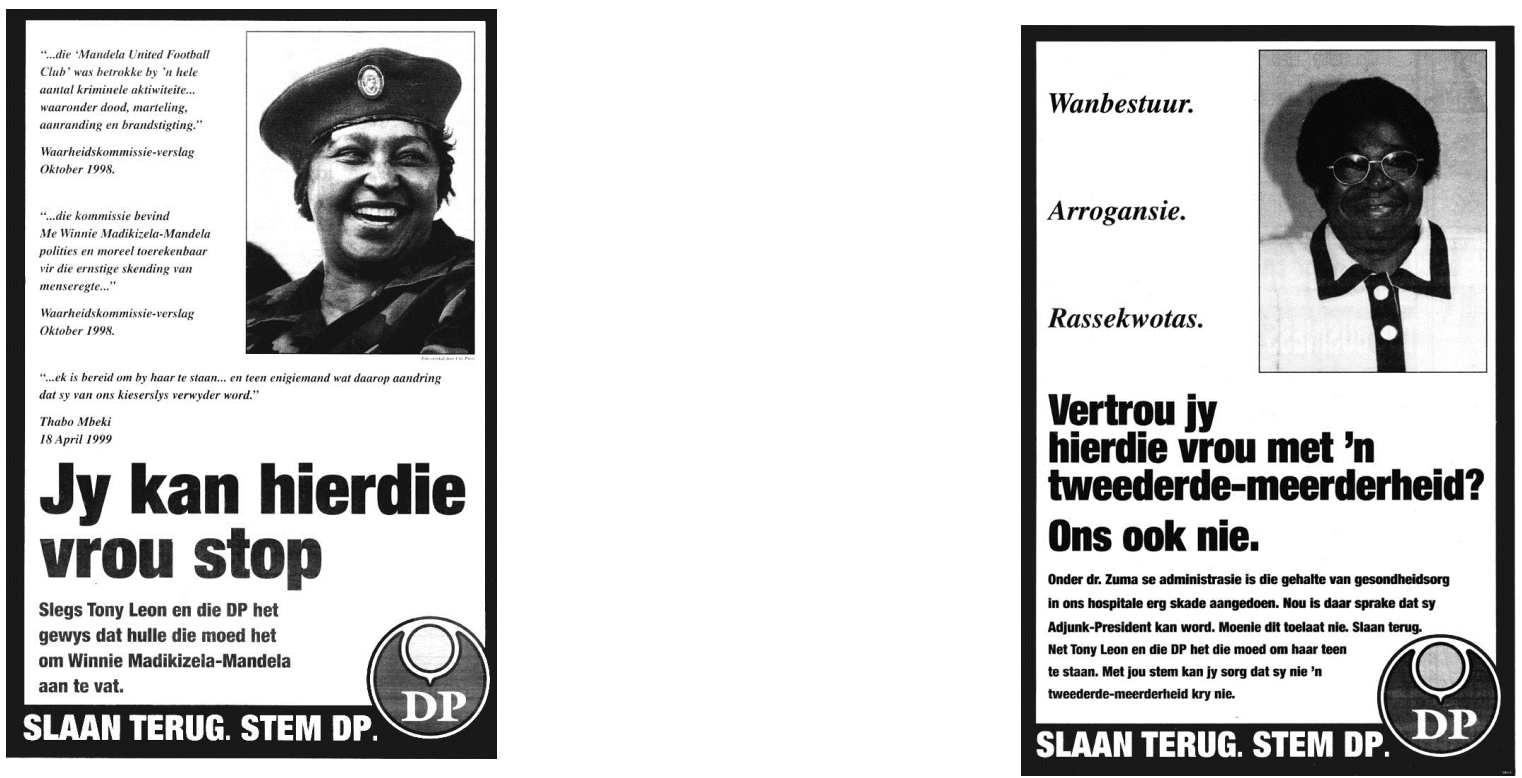